\title{
Effects of dietary sunflower oil on growth parameters, fatty acid profiles and expression of genes regulating growth and metabolism in the pejerrey (Odontesthes bonariensis) fry
}

Juan Ignacio Bertuccia, Mario Oswaldo Tovara , Suraj Unniappan ${ }^{\mathrm{b}}$, Juan Carlos Navarro $^{\mathrm{c}}$, Luis Fabián Canosa ${ }^{\mathrm{a}^{*}}$.

a Instituto de Investigaciones Biotecnológicas-Instituto Tecnológico Chascomús (IIB-INTECH), Intendente Marino Km 8.2, B7130IWA Chascomús, Buenos Aires, Argentina CC 164 (7130), Argentina. ibertucci@intech.gov.ar, Icanosa@intech.gov.ar.

b Laboratory of Integrative Neuroendocrinology, Department of Veterinary Biomedical Sciences, Western College of Veterinary Medicine, University of Saskatchewan, 52 Campus Drive, Saskatoon, SK S7N 5B4, Saskatchewan, Canada.

c Instituto de Acuicultura Torre de la Sal-Consejo Superior de Investigaciones Científicas (IATS-CSIC), 12595 Ribera de Cabanes, Castellón, España.

Corresponding author: Luis Fabian Canosa

Contact information: *Laboratorio de Neuroendocrinología Molecular, IIB-INTECH, sede Chascomús, CONICET-Universidad Nacional de San Martin, Av. Intendente Marino Km 8,200 CC 164 (7130), Chascomús, Prov. de Buenos Aires, Argentina. Tel. (542241)430323, 424045 • Fax: (542241)424048. E-mail: Icanosa@intech.gov.ar 


\section{Abstract}

Aquaculture fish diets usually contain an addition of fish oil in order to improve its nutritional value. The effect of the replacement of dietary fish oil (FO) by sunflower oil (SfO) on growth, fatty acid composition and expression of genes implicated in somatic growth, food intake and fatty acid metabolism was studied in pejerrey fry. Fry were fed per 45 days with diets containing FO/SfO ratios of: $100 \%$ FO; $50 \%$ FO - $50 \%$ SfO; $20 \%$ FO - $80 \%$ SfO and $100 \%$ SfO. No differences were detected in growth and in the total percent of saturated and monounsaturated fatty acids. Gh, ghr-I and ghr-Il showed a higher mRNA expression in head and trunk of fry fed with $100 \%$ SfO diet. Expression of igf-I/ was higher in trunk of fry fed with $100 \%$ SfO diet compared with $100 \%$ FO diet. The $\Delta 6$-desaturase gene expression was upregulated in head and trunk of fry fed with $100 \%$ SfO diet. The nucb2/nesfatin-1 gene expression decreased with increasing SfO percent in trunk of fry. We conclude that the replacement of fish oil by sunflower oil in pejerrey fry food does not affect growth, and is a viable strategy to reduce production costs of this fish.

\section{Keywords}

$\Delta 6$-desaturase, growth hormone, insulin-like growth factor, nesfatin-1, lipid, PUFA. 
1. Introduction

Pejerrey, Odontesthes bonariensis (Valenciennes, 1835), is an inland water fish from Argentina highly appreciated for the quality of its flesh that has taste, smell, texture and even chemical characteristics similar to those of expensive marine species, converting it in a good candidate for aquaculture (Somoza et al., 2008). Despite this high potential of pejerrey as an aquaculture species, no specific diets were formulated to develop and improve its aquaculture. In fact, pejerrey farming presents several difficulties related to low growth rates, high mortality in the first life stages and early sexual maturation (Grosman \& González Castelain, 1995; Miranda and Somoza, 2001). These factors made its aquaculture expensive, raising the need for improvement, in order to reduce production costs. In this sense, one approach might lie on the replacement of expensive fish oil (commonly employed to increase the nutritional value of the commercial fish food) by cheaper vegetable oils such as sunflower oil (Glencross \& Turchini, 2010). In addition, it will contribute to develop a sustainable pejerrey aquaculture since this practice would avoid the usage of wild fish (such as sardines and anchovies) to produce aqua feeds for fish farming.

Replacement of fish oil by vegetable oil in fish diet has been studied in several species, such as the atlantic salmon (Bransden et al., 2003), sea bass (Mourente et al., 2005) and rainbow trout (Turchini and Francis, 2009), among others. Particularly, the use of Sunflower oil was widely studied (Bransden et al., 2003; Wijekoon et al., 2014; Yildiz \& Sener, 1997) due to its low production cost and high availability. A general conclusion of all of these works is that the success of oil replacement depends on the fish ability to convert polyunsaturated fatty acids (PUFAs) with low 
number of unsaturations, , present in vegetable oils, into long-chain PUFAs (>20C), also referred to as highly unsaturated fatty acids (HUFAs), that are present in fish oil and are important for growth and development. In this regard, the ability of fish to synthesize long-chain PUFAs depends on the enzyme called $\Delta 6$-desaturase. This key enzyme regulates the first step in the pathway which produces arachidonic acid (AA), docosahexaenoic acid (DHA) and eicosapentaenoic acid (EPA), converting linolenic acid (LNA) and linoleic acid (LA) obtained from food to 18:4n-3 and 18:3n-6, respectively (Vagner \& Santigosa, 2011), and participates in the synthesis of DHA through the so-called Sprecher's shunt (Sprecher, 2000). Previous studies of our group show that pejerrey can express mRNA from a $\triangle 6$-desaturase like gene (paper in preparation). Moreover, studies of fatty acid composition performed in wild pejerrey larvae (Kopprio et al., 2015) and also in larvae from a related specie, the Mexican silverside (Chirostoma estor) (Palacios et al., 2007), suggest that these two fish have the ability to elongate and desaturate dietary PUFAs to long-chain PUFAs through both $\Delta 6$ and $\Delta 4$ desaturation pathways (Fonseca-Madrigal et al., 2014).

Nesfatin-1 is a peptide orphan ligand with hormone like actions, produced by the N-terminal cleavage of its precursor nucleobindin-2 (NUCB2), encoded in the nucb2 gene (Oh-I et al., 2006). Nesfatin-1 reduces food intake after central or peripheral administration in mammals (Gonzalez, Mohan, \& Unniappan, 2012;) and fish (Kerbel \& Unniappan, 2012), which supports an anorexigenic role of this hormone. In a previous work (Bertucci et al., 2017) we found that nucb2/nesfatin-1 mRNA expression is modified by fatty acids in vitro. Therefore, we aimed to study if dietary fatty acids can alter its gene expression at central and or peripheral level in 
vivo. This data, together with other results from this experiment could help to elucidate the role of nesfatin-1 in fish metabolism and food intake regulation.

Macronutrient composition of diets is an important factor regulating not only weight gain and metabolism, but also growth performance by the regulation of genes involved in somatic growth, commonly referred to as GH-IGF axis genes ( Reinecke, 2010). GH (growth hormone) is secreted from the pituitary and has been involved in different physiological functions in fish, mainly associated with somatic growth (Reinecke et al., 2005) and stress resistance (Deane and Woo, 2009; Yousefian and Shirzad, 2011), among others. This hormone exerts its action through the receptors GHR-I and GHR-II that show high expression in liver, still in early stages of development (Ozaki et al., 2006; Rhee et al., 2012). In response to this binding, the liver expresses and releases the insulin like growth factor I and II (IGF-I and IGF-II) which act in an endocrine manner promoting the somatic growth on different tissues (Wood et al., 2005). Also, IGF-I can be expressed and act in an autocrine-paracrine manner in some tissues such as brain, gastrointestinal tract, pancreas, kidney, gonads, muscle, bone and skin (Reinecke, 2010).

In summary, dietary fish oil replacement could decrease pejerrey aquaculture production costs. This might not be possible if this produce negative consequences on fish growth rate, survival and flesh properties including fatty acid composition. Therefore, the aims of this work were to determine if sun flower oil can replace fish oil in pejerrey fry food and to elucidate how this change might affect somatic growth parameters, survival rate and fatty acid composition of fish as well as the expression of genes implicated in somatic growth (gh-igf axis), food intake control (nucb2/nesfatin-1) and in fatty acid metabolism ( $\Delta 6$-desaturase). 


\section{Materials and Methods}

2.1. Fish management and experimental design

Fertilized eggs of pejerrey were acquired from Estación Hidrobiológica Chascomús (Buenos Aires, Argentina). During all the experiment, fry were maintained in $140 \mathrm{~L}$ open flow-through water system tanks (water flow of $5 \mathrm{~L} / \mathrm{min}$ ). The water salinity was $15 \mathrm{~g} / \mathrm{L}$, the oxygen concentration $8 \mathrm{ppm}$, the photoperiod was 12L:12D and the water temperature was maintained at $18{ }^{\circ} \mathrm{C}$. After hatching, fry were fed with nauplii of Artemia sp. 4 times per day during 30 days prior to the assay. One week before the onset of the experiment, a co-feeding schedule with Artemia nauplii and a commercial starter feed (crude protein, $43 \%$; crude fat, $3 \%$; crude fiber, $3 \%$; Shullet bebe ${ }^{\circledR}$, Shulet, Argentina) was established. After this adaptation period, fish were divided in 12 tanks ( $n=52$ fish/tank). Four experimental groups were established ( $n=3$ tanks/group), each fed until apparent satiety 3 times per day with diets containing the same composition except from different percent of fish oil (FO)/sunflower oil (SfO), as described in TABLE 1. The objective of this experiment was to replace partially or totally the fraction of fish oil added as ingredient of aquafeed formulation and the diets names refer to the replacement of this fraction of fish oil by sunflower oil and no to the overall lipid content of the diet which is composed by other oil sources such as lecithin, fish meal and Hake fillet. The proximal composition was performed according to AOAC (1990) methods. Crude protein was estimated as $6.25 \times$ total nitrogen $(\mathrm{N})$, determined using the Semi-micro Kjeldahl method. Crude lipid was determined gravimetrically of the sulphuric ether extract of $1 \mathrm{~g}$ samples. Moisture was measured gravimetrically after drying in an 
oven at $105^{\circ} \mathrm{C}$ for $3 \mathrm{~h}$, and the ash content by combustion in a muffle at $550^{\circ} \mathrm{C}$ for 6 h. Fatty acid composition of each diet was also determined by gas chromatography with FID detector of fatty acid methyl esters (FAME) prepared from aliquots of total lipid extracted by the Folch method (Folch et al., 1957). Fatty acid profile of diets are shown in TABLE S1 (supplementary data). Food was weighed every day before the first meal and after the last one in order to calculate the daily food consumption. This parameter was calculated as the $\mathrm{g}$ of food consumed per day in each tank divided by the number of fry presents in each tank. Total number, biomass and standard length (Ls) of fry from each tank were measured at day 0 (before start of the assay) and at days 15,30 and 45 . We were unable to collect brain, pituitary, gut, liver and muscle due to the small size of the fry. Instead, samples of head (with no gills, head-kidney and heart), trunk (from the gills to the anus) and tail (from the anus to the end of the caudal fin) were frozen in liquid nitrogen and stored at $-80^{\circ} \mathrm{C}$ until total RNA extraction.

\subsection{Total RNA extraction and real-time quantitative PCR (RT-qPCR) analysis}

Total RNA from fish tissues was extracted using the Ambion® TRIzol $\circledast$ Reagent (Life Technologies, USA) following the protocol provided by the manufacturer. Tissues were initially disrupted using a PRO 200 homogenizer (PRO Scientific Inc, USA) and $1 \mu \mathrm{g}$ of total RNA was reverse transcribed into cDNA using SuperScript II ReverseTM Transcriptase (Invitrogen, USA). Expression of the genes was measured by real-time quantitative PCR (RT-qPCR) according to Bertucci et al., 2017. The efficiency of the amplification for all genes studied was $95-100 \%$. Gene expression levels were calculated by the $2-\Delta \Delta$ Ct comparative threshold cycle 
(Ct) method, where $\Delta \mathrm{Ct}=\Delta \mathrm{Ct}$ sample $-\Delta \mathrm{Ct}$ reference (Livak and Schmittgen, 2001).

All primer sequences are shown in TABLE S2 (supplementary data).

\subsection{Fry fatty acid composition}

Total lipids and FA from lyophilized 6 individuals (randomly selected) were analyzed as described in Guinot et al., (2013). When in doubt, identity of FA was further assessed through GC-MS after splitless injection in an Agilent 6850 Gas Chromatograph system, equipped with a Sapiens-5MS $(30 \mathrm{~m} \times 0.25 \mu \mathrm{m} \times 0.25 \mu \mathrm{m})$ capillary column (Teknokroma, Sant Cugat del Vallés, Barcelona, Spain) coupled to a 5975 series MSD (Agilent Technologies, Santa Clara, CA, USA).

\subsection{Statistical analysis}

Data were analyzed by one-way ANOVA, followed by post hoc StudentNewman-Keuls (SNK) test at a significance level of $P<0.05$. Data that failed to pass homogeneity and normality tests were log-transformed and re-tested. All tests were performed using SigmaPlot Version 12.0 and Infostat Version 2008, softwares. The FA profiles obtained were integrated chemometrically in a principal component analysis (PCA) model. All the FAs were introduced in the model as variables, but only those showing communality higher than 0.5 were used for the final output. The score plot obtained after the generation of the two principal components was used to identify patterns of distribution of FA among dietary treatments. Statistical analyses were performed with the SPSS for Windows 15.0 statistical package (SPSS Inc., Chicago, IL, USA). 
3. Results

3.1. Growth and food intake

After 45 days of feeding with diets containing different percent of FO/SfO, pejerrey fry almost triplicated their initial weight in all cases, with no statistically significant differences $(p>0.05)$ detected among the different groups (TABLE 2). Additionally, the body weight increase (BWI) and the specific growth rate (SGR) were not significantly different $(p>0.05)$ among groups throughout the duration of the assay. These results are listed in TABLE 2. As is shown in TABLE 2, we did not find any difference $(p>0.05)$ in the standard length among groups of fish fed with the different experimental diets after 45 days. The condition factor $(\mathrm{K})$ was around 0.6 for all treatments during the period of the assay (TABLE 2). Furthermore, the survival percent (TABLE 2), together with number of fry per treatment (TABLE 2), indicates that the four diets tested produced the same rates of mortality, without significant differences ( $p>0.05)$ among groups. The daily food consumption (grams of dry matter of food taken per fry) in the different experimental groups was as follows: $0.279 \pm 0.004$ for $100 \%$ FO treatment; $0.279 \pm 0.002$ for $50 \%$ SfO treatment; 0.310 \pm 0.020 for $80 \%$ SfO treatment and $0.310 \pm 0.010$ for $100 \%$ SfO treatment (TABLE 2). Statistical analysis of these values indicates that no significant differences $(p>0.05)$ in food intake rates are present among groups fed with the different experimental diets. Besides, no significant differences $(p>0.05)$ among groups were observed for the feed efficiency ratio, which show a value around 0.8 - $1 \mathrm{~g} / \mathrm{g}$ DM for all treatments (TABLE 2). 
3.2. Influence of dietary lipid source on gh-igf axis, $\Delta 6$-desaturase and nucb2/nesfatin-1 gene expression

Quantification of $g h$ mRNA expression was performed in head of fry, because we were unable to take pituitary or complete brain. As is shown in FIGURE 1a, after 45 days of feeding with the experimental diets no differences $(p>0.05)$ in $g h$ expression was observed among groups fed with $100 \% \mathrm{FO}, 50 \%$ SfO and $80 \% \mathrm{SfO}$ diets. However, gh showed a higher expression $(p<0.05)$ in head of fry fed with diet containing $100 \%$ SfO compared with the other three treatments. Gene expression of GH receptors was measured in trunk (FIGURE $1 \mathrm{~b}$ ) instead of liver, because by the small size of fry we were unable to collect this tissue. We found that $g h r-I$ and $g h r-I l$ mRNA expression increased $(p<0.05)$ in fish fed with $100 \%$ SfO diet, compared to those fed with $100 \%$ FO, $50 \%$ SfO and $80 \%$ SfO diets. No differences $(p>0.05)$ in the expression of these receptors were found in $100 \% \mathrm{FO}, 50 \% \mathrm{SfO}$ and $80 \% \mathrm{SfO}$ treatments. Concerning IGFs, mRNA encoding igf-I was detectable in head but no differences $(p>0.05)$ in expression were observed among experimental groups (FIGURE 1c). Expression of this gene was undetectable in trunk and tail of pejerrey fry in any of the experimental groups. Gene expression of igf-/l was not significantly different $(p>0.05)$ among groups in head and tail (FIGURE 1d), but a higher expression $(p<0.05)$ was observed in the trunk of fry that were fed with $100 \%$ SfO diet compared with fish fed with $100 \% \mathrm{FO}, 50 \% \mathrm{SfO}$ and $80 \%$ SfO diets.

As shown in FIGURE 2, the $\Delta 6$-desaturase gene expression was upregulated $(p<0.05)$ in head and trunk (FIGURE $2 a)$ of pejerrey fry feed with diet containing $100 \%$ of SfO as an oil source. No differences ( $p>0.05)$ were observed between treatments in tail (FIGURE 2a). The nucb2/nesfatin-1 gene expression in the head 
of pejerrey fry did not change with the dietary FO replacement (FIGURE 2b). Nonetheless, a decrease $(p<0.05)$ of nucb2/nesfatin-1 gene expression with an increase in the dietary SfO percent was observed in the trunk of pejerrey fry (FIGURE 2b).

\subsection{Lipid and fatty acid composition of pejerrey fry}

In TABLE 3, a list of fatty acids as a percent of total fatty acids from total lipids of pejerrey fry from each dietary group is provided. The substitution of dietary FO with SfO generates a decrease $(p<0.05)$ in the percent of fatty acids of the $n-3$ group, such as alfa-linolenic acid, EPA and DHA. Also, the dietary fish oil replacement generates an increase $(p<0.05)$ of the $n-6$ fatty acids, such as linoleic acid and docosapentaenoic acid. In summary, no differences $(p>0.05)$ were observed in the total percent of saturated and monounsaturated fatty acids present in fry feed with the four experimental diets, but, an increase $(p<0.05)$ in the total amount of PUFA of the $n-6$ group and a decrease $(p<0.05)$ of PUFA of the $n-3$ group when the dietary FO is replaced partially or totally by SfO was observed. TABLE 3, also shows the DHA/EPA ratio. This ratio increases $(p<0.05)$ when the percent of dietary SfO increases from $0 \%$ to $80 \%$., while no differences $(p>0.05)$ were observed between $80 \%$ SfO and $100 \%$ SfO.

The PCA results are summarized in FIGURE 3a. The two first components accounted for $83 \%$ of total variance. First component (55\% variance) was clearly associated to oil substitution in the diets, with $n-6$ variables typical from SfO loading on the negative side of the axis, away from n-3 ones who loaded on the positive side. As for the second component that accounted for $28 \%$ of total variance, AA and C18 
and C20 saturates loaded heavily on the negative side. This results in a score plot (FIGURE $3 b$ ) that allows to segregate clearly the dietary groups on the first component, with the fatty acid patterns of fish fed FO separated from those fed intermediate substitution $(50 \% \mathrm{SfO})$ who in turn are also clearly distinct from the two most substituted dietary groups ( $80 \% \mathrm{SfO}$ and $100 \% \mathrm{SfO})$.

\section{Discussion}

In this work, we report a substitution with sunflower oil in diets of pejerrey fry, without compromising somatic growth and weight gain. Additionally, results indicate that replacement of fish oil added as ingredient in the diet might be total, at least in the first stages of pejerrey development. These results are in concordance with works mentioned above, in which authors reported that fish oil replacement with sunflower oil does not affect growth rate, final weight, weight gain, total feed consumption, feed efficiency ratio and survival of the species tested (Bransden et al., 2003; Mourente et al., 2005; Turchini and Francis, 2009).

One important aspect observed in the present study is that feed consumption and feed efficiency ratio were not significantly different among fish fed with the four experimental diets tested, indicating that pejerrey might be able to obtain energy and structural precursors from fatty acids with low degree of unsaturation as those present in sunflower oil since early stages of development. Survival rate is an important issue which influences the production cost of commercial fish culture. It has been demonstrated that a manipulation of dietary $n-6 / n-3$ ratio affects fish pathogen resistance and immune parameters, such as the activity of the alternative complement pathway or the phagocytic activity of head kidney macrophages 
(Montero et al., 2008). This fact makes it necessary to evaluate if dietary fish oil replacement affects the survival rate of fish treated in order to discard any negative effect that can generate a decrement in fish production. In our study, we observed that mortality ratios show no significant differences among experimental groups. Indeed, survival percent in each group was around $70-75 \%$, which is consistent with previous reports by other authors (Miranda et al., 2006) and can be considered as normal in this developmental stage. These results indicate that replacement of FO with SfO at least in early stages of pejerrey development, does not compromise fry survival.

The GH-IGF system plays a major role coordinating growth of vertebrates (Reindl \& Sheridan, 2012) and could be used as a marker of nutritional status and growing performance (Pérez-Sánchez \& Le Bail, 1999). In fish, gh gene expression occurs very early in development (Martí-Palanca \& Pérez-Sánchez, 1994), and the increase in body weight reported in gilthead sea bream larvae after its oral administration suggests a growth promoting effect of $\mathrm{GH}$ during early development (Ben-Atia et al., 1999). Ghr-I mRNA expression has been reported in Chilean flounder larvae at 8 days after hatching (dah) in somites and head, and at 9.5 dah in almost the whole larvae (Fuentes et al., 2008). Early mRNA expression of igf-I and igf-Il was also observed in gilthead sea bream (Perrot et al., 1999). In the present work, we found a higher mRNA expression of $g h$ in head and of $g h r-I$ and $g h r-I I$ in trunk of fish fed with $100 \%$ SfO diet. Moreover, the expression of igf-II was higher in trunk of fish from the same experimental group. Together, all these observations may indicate an action mediated by GH-IGF system in response to a total replacement of dietary fish oil, although this response would not necessarily imply 
any additional stimulation of somatic growth. Fasting and malnutrition have been previously associated with changes in GH-IGF axis (Perez-sanchez et al., 1995; Wilkinson et al., 2006). Authors from these works found that, during food deprivation, plasmatic levels of $\mathrm{GH}$ increase, while a decrease is observed for plasmatic levels of IGF-I and IGF-II and mRNA levels of $g h$ receptors and igf-I in liver. Although we found a high expression of $g h$ in fry fed with $100 \%$ SfO diet, which could be correlated with high plasmatic levels of $\mathrm{GH}$, but contrary to the results described above, we observed a concomitant increase in the mRNA expression of ghr-l, ghr-Il and igf-Il. Thus, this could indicate that the change in mRNA expression of gh-igf axis in response to $100 \% \mathrm{SfO}$ diet is not an indication of malnutrition in the pejerrey fry. It would be interesting to further study if this upregulation of $g h, g h r-I, g h r-I /$ and igf-Il could also have an effect on somatic growth in subsequent stages of pejerrey development. Since we did not observe any signal of differential somatic growth between $100 \%$ SfO group and the other three treatment groups, we hypothesized that the over expression of $g h, g h r-I, g h r-I l$ and igf-Il might be related with lipid metabolism and energy mobilization (Perez-Sanchez et al., 2002; Vijayakumar et al., 2010). Concerning igf-I mRNA expression, we were able to detect it only in the head of pejerrey fry but not in trunk or tail. Due to the small size of fry tissues, the whole trunk and tail were to be used instead of liver and muscle, thus, it is unavoidable that samples contain mRNA from other tissues as well and thus a relative lower amount of igf-I mRNA which might make it gene expression undetectable. This fact might indicate a higher amount of igf-I/ mRNA present in pejerrey fry compared with igf-I at the moment of sample collection. In head, both 
genes were expressed at the same level in each dietary treatment, indicating a tissue specific action of IGF-I and IGF-II, at least in this stage of pejerrey.

In order to know how dietary composition could affect fatty acid metabolism, we studied the influence of dietary fish oil replacement on pejerrey $\Delta 6$-desaturase tissue gene expression. Although $\Delta 4$-desaturase activity has been reported in other species of the same family (Chisrostoma estor, Fonseca-Madrigal et al., 2014), thus allowing DHA synthesis independently of Sprecher's shunt, $\Delta 6$-desaturase expression seems a better marker of the effects of putative nutritional regulation driven by SfO substitution, since $\Delta 6$-desaturases are expected to act over $18: 2 n-6$ and $18: 3 n-3$ in the first steps leading to the synthesis of long-chain PUFA either through direct $\Delta 4$ activity or through the above mentioned Sprecher's pathway. We found that mRNAs levels encoding $\Delta 6$-desaturase were higher in head and trunk of fry fed with $100 \%$ SfO diet compared with the other groups that were fed with a different mix of SfO and FO. This result is in concordance with previous studies in other fish species reporting a nutritional regulation of $\Delta 6$-desaturase gene expression by the dietary oil source (Ren et al., 2012; Sarker et al., 2011). The observed response of $\Delta 6$-desaturase gene expression to total FO replacement was tissue specific, since the high expression mentioned above was not found in in tail. Therefore, considering that the tail portion of pejerrey fry is composed mainly by muscle, we can consider that changes in $\Delta 6$-desaturase gene expression in head and trunk were not due to the muscle tissue present there. We attribute those changes to other organs such as brain in head (rich in long-chain PUFA) and liver (lipid metabolism), intestine (absorption) and gonads (rich in long-chain PUFA) in trunk of pejerrey fry. This might indicate a dietary regulation of PUFA and HUFA 
synthesis in central and peripheral tissues such as those mentioned above. While a higher expression of $\Delta 6$-desaturase was observed in $100 \%$ SfO fed fry, no differences were observed among the other groups despite the decreasing levels of fish oil. This could be explained in two ways. On one hand, a dietary FO content of at least $20 \%$, presumably helped by the $\Delta 4$ activity, meets the requirements of PUFAs and HUFAs for pejerrey fry. On the other hand, a decrease in the dietary FO content with the concomitant reduction of dietary PUFAs and HUFAs could promote compensatory changes in $\Delta 6$-desaturase activity not observed at gene expression level, but presumably taking place at enzyme activity or protein translation levels. Thus, changes in gene expression would be observed only when dietary PUFAs and HUFAs content fall below a minimum level, probably below $20 \%$.

Although the substitution of dietary FO with oil from plant sources is a topic of increasing interest in aquaculture, only few studies have been done in order to know how that replacement could affect the expression of peptides involved in food intake regulation (Bonacic et al., 2016). In this experiment, we tested how this replacement affects nucb2/nesfatin-1 mRNA expression in pejerrey fry. While no effects were found in head, a decrement in the nucb2/nesfatin-1 mRNA expression with an increase in the dietary SfO percent was found in trunk. In the work by Bonacic et al., (2016), the authors found that fish oil and plant oil led to differential regulation of genes involved in the control of food intake, although no apparent pattern of expression was detected for orexigenic and anorexigenic genes. As we observed in a previous work (Bertucci et al., 2017), fatty acids alter the expression of nucb/nesfatin-1 in goldfish intestine and hepatopancreas organ culture, suggesting 
an involvement of nesfatin-1 in the fatty acids metabolism. Additionally, in that work we found a downregulation of nucb2/nesfatin-1 gene expression by the oleic acid, which is present in a high proportion in the sunflower oil. These in vitro results are consistent with the in vivo results found in the present paper. Therefore, taking in consideration these results, we hypothesize that changes found in the nucb2/nesfatin-1 mRNA expression could be associated not only with food intake regulation but also with changes in the fatty acid metabolism.

We also studied the fatty acid composition from total lipids of the complete pejerrey fry. Results show that the dietary FO replacement with SfO generates a decrease in the total amount of the n-3 PUFAs and an increase in the n-6 PUFAs. This change is predictable, because the increases in the dietary SfO elevate the amount of n-6 PUFAs which are typical components of the vegetable oils, and a decrease in the n-3 which are presents in fish oil. Despite this fact, pejerrey fry were able to generate EPA and DHA (n-3 PUFAs) and DPA (n-6 PUFA), which are the ultimate products of each biosynthetic pathway, even when FO is not added in the diet as suggested by the increase of DHA/EPA and DPA/AA ratios. Our results, together with those from Kopprio et al. (2015), suggests that pejerrey has the capability to desaturate and elongate fatty acids which are necessary for survival and growth. As n-3 PUFAs are a desirable component of fish flesh and the replacement of dietary FO by SfO does not decrease dramatically the total amount of n-3 PUFAs (specifically the amount of DHA and EPA) in whole fry, this strategy could be useful for pejerrey aquaculture by reducing the production costs. 
In summary, the present work show for the first time in pejerrey that the supplemented fraction of dietary fish oil could be totally replaced by sunflower oil since early stages of development without compromising fish growth, body weight increase and other important aquaculture parameters, such as survival rate. Moreover, we found a high expression of gh-igf axis genes in response to complete fish oil replacement. We attribute this to changes in lipid metabolism, although future studies are required to investigate this and whether these changes can generate an increase in somatic growth. Concerning lipid metabolism, we show a tissue specific regulation of $\Delta 6$-desaturase expression by the dietary fish oil content. This result together with the fatty acid composition analysis of fry support the idea that pejerrey has the enzymes necessary to synthesize PUFAs from monounsaturated precursors as those present in vegetable oils. In conclusion, replacement of fish oil by sunflower oil in pejerrey fry feed does not affect growth and this strategy could be used to reduce production costs of this commercial fish. 


\section{Acknowledgements}

This work was partially funded by Agencia Nacional de Promoción Científica y Tecnológica (ANPCyT, Argentina; PICT 2010-1493) and Consejo Nacional de Investigaciones Científicas y Tecnológicas (CONICET; PIP 2014/0595) to LFC. Lipid analyses were carried out under the framework of projects AGL2013-40986-R from MINECO, and PROMETEO 2014/085. Part of this work conducted at the laboratory of SU was supported by a Discovery grant from the Natural Sciences and Engineering Research Council (NSERC) of Canada, to SU. JIB was recipient of a doctoral fellowship from ANPCyT (Argentina) and is doctoral fellow from CONICET (Argentina), and MOT was recipient of Latin American doctoral fellowships from CONICET (Argentina). Authors would like to thank Ricardo Boeri and co-workers from Instituto Nacional de Tecnología Industrial (INTI)-Mar del Plata, for providing us with the experimental diets and composition data, and Javier Eduardo Herdman for his valuable assistance in fish feeding and handling. Miguel A. Montolio and Eva Herrero assisted in lipid analyses. 


\section{References}

Association of Official Analytical Chemists, 1990. Arlington, VA. pp. 684.

Ben-Atia, I., Fine, M., Tandler, a, Funkenstein, B., Maurice, S., Cavari, B., \& Gertler, a. (1999). Preparation of recombinant gilthead seabream (Sparus aurata) growth hormone and its use for stimulation of larvae growth by oral administration. General and Comparative Endocrinology, 113(1), 155-164. http://doi.org/10.1006/gcen.1998.7192

Bertucci, J. I., Blanco, A. M., Canosa, L. F., \& Unniappan, S. (2017). Glucose, Amino Acids and Fatty Acids Directly Regulate Ghrelin and NUCB2/Nesfatin-1 in the Intestine and Hepatopancreas of Goldfish (Carassius auratus) In Vitro. Comparative Biochemistry and Physiology Part A: Molecular \& Integrative Physiology, 206, 2435. https://doi.org/10.1016/j.cbpa.2017.01.006

Bonacic, K., Campoverde, C., Gómez-Arbonés, J., Gisbert, E., Estevez, A., \& Morais, S. (2016). Dietary fatty acid composition affects food intake and gut-brain satiety signaling in Senegalese sole (Solea senegalensis, Kaup 1858) larvae and post-larvae. General and Comparative Endocrinology, 228, 79-94. http://doi.org/10.1016/j.ygcen.2016.02.002

Bransden, M. P., Carter, C. G., \& Nichols, P. D. (2003). Replacement of fish oil with sunflower oil in feeds for Atlantic salmon (Salmo salar L.): effect on growth performance, tissue fatty acid composition and disease resistance. Comparative Biochemistry and Physiology Part B: Biochemistry and Molecular Biology, 135(4), 611-625. http://doi.org/10.1016/S1096-4959(03)00143-X

Deane, E. E., \& Woo, N. Y. S. (2009). Modulation of fish growth hormone levels by salinity, temperature, pollutants and aquaculture related stress: A review. Reviews in Fish Biology and Fisheries. http://doi.org/10.1007/s11160-008-9091-0

Folch, J., Lees, M., Sloane-Stanley, G., (1957). A simple method for the isolation and purification of total lipids from animal tissues. Journal of Biologilcal Chemistry 226, 497-509.

Fonseca-Madrigal, J., Navarro, J. C., Hontoria, F., Tocher, D. R., Martinez-Palacios, C. a., \& Monroig, O. (2014). Diversification of substrate specificities in teleostei Fads2: characterization of $\Delta 4$ and $\Delta 6-\Delta 5$ desaturases of Chirostoma estor. The Journal of Lipid Research, 55(7), 1408-1419. http://doi.org/10.1194/jlr.M049791

Fuentes, E., Poblete, E., Reyes, A. E., Vera, M. I., Alvarez, M., \& Molina, A. (2008). Dynamic expression pattern of the growth hormone receptor during early development of the Chilean flounder. Comparative Biochemistry and Physiology BBiochemistry \& Molecular Biology, 150(1), 93-102. http://doi.org/DOI 10.1016/j.cbpb.2008.01.009

Glencross, B., \& Turchini, G. (2010). Fish Oil Replacement in Starter, Grow-Out, and Finishing Feeds for Farmed Aquatic Animals. In Fish Oil Replacement and Alternative Lipid Sources in Aquaculture Feeds (pp. 373-404). CRC Press. http://doi.org/doi:10.1201/9781439808634-c12 
Gonzalez, R., Mohan, H., \& Unniappan, S. (2012). Nucleobindins: bioactive precursor proteins encoding putative endocrine factors? General and Comparative Endocrinology, 176(3), 341-6. http://doi.org/10.1016/j.ygcen.2011.11.021

Grosman, F., \& González Castelain, J. (1995). Experiencias de alimentación y crecimiento con alevinos de pejerrey (Odontesthes bonariensis) dirigidas a optimizar la siembra. Revista de Ictiología Argentina., 4(1-2), 5-9.

Kerbel, B., \& Unniappan, S. (2012). Nesfatin-1 Suppresses Energy Intake, Colocalises Ghrelin in the Brain and Gut, and Alters Ghrelin, Cholecystokinin and Orexin mRNA Expression in Goldfish. Journal of Neuroendocrinology, 24(2), 366377. http://doi.org/10.1111/j.1365-2826.2011.02246.x

Guinot, D., Monroig, Ó., Navarro, J. C., Varó, I., Amat, F., \& Hontoria, F. (2013). Enrichment of Artemia metanauplii in phospholipids and essential fatty acids as a diet for common octopus (Octopus vulgaris) paralarvae. Aquaculture Nutrition, 19(5), 837-844. https://doi.org/10.1111/anu.12048

Kopprio, G. A., Graeve, M., Kattner, G., \& Lara, R. J. (2015). Fatty acid composition of wild Odontesthes bonariensis (Valenciennes 1835) larvae: Implications on lipid metabolism and trophic relationships. Journal of Applied Ichthyology, 31, 752-755. http://doi.org/10.1111/jai.12786

Livak, K. J., \& Schmittgen, T. D. (2001). Analysis of relative gene expression data using real-time quantitative PCR and. Methods, 25, 402-408. http://doi.org/10.1006/meth.2001.1262

Martí-Palanca, H., \& Pérez-Sánchez, J. (1994). Developmental regulation of growth hormone binding in the gilthead sea bream, Sparus aurata. Growth Regulation, 4(1), 14-19.

Miranda, L. a., Berasain, G. E., Velasco, C. a M., Shirojo, Y., \& Somoza, G. M. (2006). Natural spawning and intensive culture of pejerrey Odontesthes bonariensis juveniles. Biocell, 30(1), 157-162.

Miranda, L. A., \& Somoza, G. M. (2001). Biología reproductiva del pejerrey Odontesthes bonariensis: Diferenciación sexual y endocrinología de la reproducción. Aspectos básicos y su potencial aplicación en acuicultura. Fundamentos Biológicos, Económicos Y Sociales Para Una Correcta Gestión Del Recurso Pejerrey. F Grosman Ed. Editorial Astyanax, Buenos Aires, 41-45.

Montero, D., Grasso, V., Izquierdo, M. S., Ganga, R., Real, F., Tort, L., Caballero M., Acosta, F. (2008). Total substitution of fish oil by vegetable oils in gilthead sea bream (Sparus aurata) diets: effects on hepatic Mx expression and some immune parameters. Fish \& Shellfish Immunology, 24(2), 147-55. http://doi.org/10.1016/j.fsi.2007.08.002

Mourente, G., Good, J. E., \& Bell, J. G. (2005). Partial substitution of fish oil with rapeseed, linseed and olive oils in diets for European sea bass (Dicentrarchus labrax L.): effects on flesh fatty acid composition, plasma prostaglandins E2 and F2a, immune function and effectiveness of a fish oil fin. Aquaculture Nutrition, 11(1), 2540. 
Oh-I, S., Shimizu, H., Satoh, T., Okada, S., Adachi, S., Inoue, K., Eguchi, H., Yamamoto M., Imaki, T., Hashimoto, K., Tsuchiya, T., Monden, T., Horiguchi, K., Yamada, M., Mori, M. (2006). Identification of nesfatin-1 as a satiety molecule in the hypothalamus. Nature, 443(7112), 709-712. Retrieved from http://dx.doi.org/10.1038/nature05162

Ozaki, Y., Fukada, H., Tanaka, H., Kagawa, H., Ohta, H., Adachi, S., Hara, A., Yamauchi, K. (2006). Expression of growth hormone family and growth hormone receptor during early development in the Japanese eel (Anguilla japonica). Comparative Biochemistry and Physiology. Part B, Biochemistry \& Molecular Biology, 145(1), 27-34. http://doi.org/10.1016/j.cbpb.2006.05.009

Palacios, E., Racotta, I. S., Aparicio, B., Arjona, O., \& Martínez-Palacios, C. A. (2007). Lipid classes and fatty acids during embryogenesis of captive and wild silverside (Chirostoma estor estor) from Pátzcuaro Lake. Fish Physiology and Biochemistry, 33(1), 81-91. http://doi.org/10.1007/s10695-006-9119-0

Perez-Sanchez, J., Calduch-Giner, J. a, Mingarro, M., de Celis, S. V. R., GomezRequeni, P., Saera-Vila, a, ... Valdivia, M. M. (2002). Overview of fish growth hormone family. New insights in genomic organization and heterogeneity of growth hormone receptors. Fish Physiology and Biochemistry, 27(3-4), 243-258. http://doi.org/10.1023/B:FISH.0000032729.72746.c8

Perez-Sanchez, J., \& Le Bail, P.,Y. (1999). Growth hormone axis as marker of nutritional status and growth performance in fish. Aquaculture, 177(1), 117-128.

Perez-sanchez, J., Martipalanca, H., \& Kaushik, S. J. (1995). Ration Size and Protein-Intake Affect Circulating Growth-Hormone Concentration, Hepatic GrowthHormone Binding and Plasma Insulin-Like Growth-Factor-I Immunoreactivity in a Marine Teleost, the Gilthead Sea Bream (Sparus-Aurata). Journal of Nutrition, 125(3), 546-552.

Perrot, V., Moiseeva, E. B., Gozes, Y., Chan, S. J., Ingleton, P., \& Funkenstein, B. (1999). Ontogeny of the insulin-like growth factor system (IGF-I, IGF-II, and IGF-1R) in gilthead seabream (Sparus aurata): expression and cellular localization. General and Comparative Endocrinology, 116, 445-460. http://doi.org/10.1006/gcen.1999.7337

Reindl, K. M., \& Sheridan, M. A. (2012). Peripheral regulation of the growth hormoneinsulin-like growth factor system in fish and other vertebrates. Comparative Biochemistry and Physiology. Part A, Molecular \& Integrative Physiology, 163(3-4), 231-45. http://doi.org/10.1016/j.cbpa.2012.08.003

Reinecke, M. (2010). Influences of the environment on the endocrine and paracrine fish growth hormone-insulin-like growth factor-I system. Journal of Fish Biology, 76(6), 1233-54. http://doi.org/10.1111/j.1095-8649.2010.02605.x

Reinecke, M., Björnsson, B. T., Dickhoff, W. W., McCormick, S. D., Navarro, I., Power, D. M., \& Gutiérrez, J. (2005). Growth hormone and insulin-like growth factors in fish: where we are and where to go. General and Comparative Endocrinology, 142(1), 20-24. 
Ren, H., Yu, J., Xu, P., \& Tang, Y. (2012). Influence of dietary fatty acids on muscle fatty acid composition and expression levels of $\Delta 6$ desaturase-like and Elovl5-like elongase in common carp (Cyprinus carpio var. Jian). Comparative Biochemistry and Physiology. Part B, Biochemistry \& Molecular Biology, 163(2), 184-92. http://doi.org/10.1016/j.cbpb.2012.05.016

Rhee, J.-S., Kim, B.-M., Seo, J. S., Kim, I.-C., Lee, Y.-M., \& Lee, J.-S. (2012). Cloning of growth hormone, somatolactin, and their receptor mRNAs, their expression in organs, during development, and on salinity stress in the hermaphroditic fish, Kryptolebias marmoratus. Comparative Biochemistry and Physiology. Part A, Molecular \& Integrative Physiology, 161(4), 436-42. http://doi.org/10.1016/j.cbpa.2012.01.004

Sarker, M. A.-A., Yamamoto, Y., Haga, Y., Sarker, M. S., Miwa, M., Yoshizaki, G., \& Satoh, S. (2011). Influences of low salinity and dietary fatty acids on fatty acid composition and fatty acid desaturase and elongase expression in red sea bream Pagrus major. Fisheries Science, 77(3), 385-396. http://doi.org/10.1007/s12562011-0342-y

Somoza, G. M., Miranda, L. a., Berasain, G. E., Colautti, D., Remes Lenicov, M., \& Strüssmann, C. a. (2008). Historical aspects, current status and prospects of pejerrey aquaculture in South America. Aquaculture Research, 39(7), 784-793. http://doi.org/10.1111/j.1365-2109.2008.01930.x

Sprecher, H. (2000). Metabolism of highly unsaturated n-3 and n-6 fatty acids. Biochimica et Biophysica Acta (BBA)-Molecular and Cell Biology of Lipids, 1486(2), 219-231.

Turchini, G. M., \& Francis, D. S. (2009). Fatty acid metabolism (desaturation, elongation and beta-oxidation) in rainbow trout fed fish oil- or linseed oil-based diets. The British Journal of Nutrition, 102(1), 69-81. http://doi.org/10.1017/S0007114508137874

Vagner, M., \& Santigosa, E. (2011). Characterization and modulation of gene expression and enzymatic activity of delta- 6 desaturase in teleosts: A review. Aquaculture, 315(1-2), 131-143. http://doi.org/10.1016/j.aquaculture.2010.11.031

Vijayakumar, A., Novosyadlyy, R., Wu, Y., Yakar, S., \& LeRoith, D. (2010). Biological effects of growth hormone on carbohydrate and lipid metabolism. Growth Hormone \& IGF Research : Official Journal of the Growth Hormone Research Society and the International IGF Research Society, 20(1), 1-7. http://doi.org/10.1016/j.ghir.2009.09.002

Wijekoon, M. P. A., Parrish, C. C., \& Mansour, A. (2014). Effect of dietary substitution of fish oil with flaxseed or sunflower oil on muscle fatty acid composition in juvenile steelhead trout (Oncorhynchus mykiss) reared at varying temperatures. Aquaculture, 433, 74-81.

Wilkinson, R. J., Porter, M., Woolcott, H., Longland, R., \& Carragher, J. F. (2006). Effects of aquaculture related stressors and nutritional restriction on circulating growth factors (GH, IGF-I and IGF-II) in Atlantic salmon and rainbow trout. 
Comparative Biochemistry and Physiology. Part A, Molecular \& Integrative Physiology, 145(2), 214-24. http://doi.org/10.1016/j.cbpa.2006.06.010

Wood, A. W., Duan, C., \& Bern, H. A. (2005). Insulin-like growth factor signaling in fish. International Review of Cytology. http://doi.org/10.1016/S0074-7696(05)430041

Yildiz, M., \& Sener, E. (1997). Effect of dietary supplementation with soybean oil, sunflower oil or fish oil on the growth of seabass (Dicentrarchus labrax L. 1758). Feeding Tomorrow's Fish. Proceedings of the Workshop of the CIHEAM Network on Technology of Aquaculture in the Mediterranean TECAM, Jointly Organized by CIHEAM, FAO and IEO, Mazarron Spain, 22(: ISSN 1022-1379), 225-233.

Yousefian, M., \& Shirzad, E. (2011). The Review of the Effect of Growth Hormone on Immune System , Metabolism and Osmoregulation of Fish. Australian Journal of Basic and Applied Sciences, pp. 467-475. 


\section{Figure Legends}

Figure 1. (a) gh mRNA expression levels in head, (b) ghr-l and ghr-ll expression levels in trunk, (c) igf-I expression level in head and (d) igf-Il expression level in head, trunk and tail of fry of pejerrey after 45 days of treatment. Bars represent media \pm SE $(n=6)$. Different letters indicate significant differences among treatments (One Way ANOVA, SNK Test, $p<0.05)$. In graphs $b$ and $d$, letters indicate significant differences between treatments for each gene (b) or larvae section (d).

Figure 2. Influence of the dietary oil source on the $\Delta 6$-desaturase (a) and nucb2/nesfatin-1 (b) gene expression in the head, trunk and tail of pejerrey fry. Bars represent media $\pm S E(n=6)$. Different letters indicate significant differences among treatments (One-way ANOVA, SNK, $p<0.05$ ).

Figure 3. Component plot (a) and factor score plot (b) of the Principal Components Analysis of fatty acid composition of pejerrey fry fed with diets containing $100 \% \mathrm{FO}$; $50 \%$ SfO; $80 \%$ SfO and $100 \%$ SfO. Bars represent media \pm SE $(n=6)$. Different letters indicate significant differences among treatments (One-way ANOVA, SNK, $p<0.05)$. Close circles represent media \pm SE $(n=6)$. 
Tables

TABLE 1. Ingredients and proximate of the experimental diets.

\begin{tabular}{|c|c|c|c|c|}
\hline & $\mathbf{1 0 0} \% \mathbf{F O}$ & $\mathbf{5 0} \% \mathbf{S f O}$ & $\mathbf{8 0} \% \mathbf{S f O}$ & $\mathbf{1 0 0 \%}$ SfO \\
\hline $\begin{array}{c}\text { Ingredients (g kg -1 } \\
\text { Sample) }\end{array}$ & & & & \\
\hline CMC & 37.0 & 37.0 & 37.0 & 37.0 \\
\hline Agar & 15.0 & 15.0 & 15.0 & 15.0 \\
\hline Vitamin and Minerals $^{1}$ & 52.0 & 52.0 & 52.0 & 52.0 \\
\hline Starch & 117.0 & 117.0 & 117.0 & 117.0 \\
\hline NaCl & 30.0 & 30.0 & 30.0 & 30.0 \\
\hline Gluten & 50.0 & 50.0 & 50.0 & 50.0 \\
\hline Hake Fillet & 318.0 & 318.0 & 318.0 & 318.0 \\
\hline Fish meal ${ }^{2}$ & 318.0 & 318.0 & 318.0 & 318.0 \\
\hline Soy Lecithin & 25.0 & 25.0 & 25.0 & 25.0 \\
\hline Fish oil & 38.0 & 19.0 & 8.0 & 0.0 \\
\hline Sunflower oil & 0.0 & 19.0 & 30.0 & 38.0 \\
\hline PC (g kg -1 Sample) & & & & 18.0 \\
\hline Humidity & 55.40 & 52.40 & 73.30 & 70.40 \\
\hline Crude lipid & 159.20 & 167.00 & 182.20 & 157.10 \\
\hline Crude protein & 407.70 & 403.60 & 404.80 & 396.60 \\
\hline Ash & 203.10 & 198.40 & 156.30 & 189.50 \\
\hline Carbohydrates & 174.60 & 178.60 & 183.40 & 186.40 \\
\hline
\end{tabular}

CMC: carboxymethyl cellulose. PC: proximate composition.

1 "Vitafac Super Acqua". Provided per kg of feed: retinol, 24000 I.U.; vitamin D 3,4800 I.U.; tocopherol, 500 I.U.; vitamin $\mathrm{K}_{3}, 16 \mathrm{mg}$; thiamine, $20 \mathrm{mg}$; riboflavin, $40 \mathrm{mg}$; pyrodoxine- $\mathrm{HCl}, 30 \mathrm{mg}$; vitamin $\mathrm{B}_{12}, 0.06 \mathrm{mg}$; ascorbic acid, $300 \mathrm{mg}$; niacin, $300 \mathrm{mg}$; pantothenic acid, $80 \mathrm{mg}$; folic acid, $12 \mathrm{mg}$; biotin. $2 \mathrm{mg}$; zinc, $140 \mathrm{mg}$; iron, $200 \mathrm{mg}$; manganese, $100 \mathrm{mg}$; copper, $10 \mathrm{mg}$; cobalt, $4 \mathrm{mg}$; iodine, $3.4 \mathrm{mg}$; selenium, $6 \mathrm{mg}$.

${ }^{2} 62 \%$ of crude protein, Moliendas del Sur S.A., Mar del Plata, Argentina. 
TABLE 2. Data on growth performance, food consumption and percent of survivals of fry fed with the experimental diets for 45 days.

\begin{tabular}{|c|c|c|c|c|}
\hline & $100 \%$ FO & $\mathbf{5 0 \%}$ SfO & $\mathbf{8 0 \%}$ SfO & $100 \%$ SfO \\
\hline Initial BW (g) & $0.061 \pm 0.002$ & $0.065 \pm 0.002$ & $0.064 \pm 0.002$ & $0.062 \pm 0.002$ \\
\hline Final BW (g) & $0.16 \pm 0.02$ & $0.16 \pm 0.01$ & $0.18 \pm 0.01$ & $0.16 \pm 0.01$ \\
\hline WG (g) & $0.10 \pm 0.01$ & $0.09 \pm 0.01$ & $0.11 \pm 0.01$ & $0.01 \pm 0.01$ \\
\hline BWI \% & $158 \pm 23$ & $140 \pm 7$ & $179 \pm 9$ & $157 \pm 10$ \\
\hline SGR \% in weight & $2.1 \pm 0.2$ & $1.9 \pm 0.1$ & $2.3 \pm 0.1$ & $2.1 \pm 0.1$ \\
\hline Initial SI (mm) & $20.0 \pm 0.5$ & $20.2 \pm 0.5$ & $20.0 \pm 0.5$ & $19.7 \pm 0.5$ \\
\hline Final SI (mm) & $29 \pm 1$ & $27 \pm 1$ & $29 \pm 1$ & $28 \pm 1$ \\
\hline SGR \% in length & $0.64 \pm 0.04$ & $0.76 \pm 0.04$ & $0.64 \pm 0.05$ & $0.81 \pm 0.06$ \\
\hline Initial K & $0.57 \pm 0.02$ & $0.58 \pm 0.02$ & $0.59 \pm 0.02$ & $0.61 \pm 0.04$ \\
\hline Final K & $0.60 \pm 0.03$ & $0.57 \pm 0.04$ & $0.54 \pm 0.03$ & $0.55 \pm 0.01$ \\
\hline FFC (g DM/ & $0.279 \pm 0.004$ & $0.279 \pm 0.002$ & $0.310 \pm 0.020$ & $0.310 \pm 0.010$ \\
\hline larvae/ day) & $77 \pm 2$ & $73 \pm 4$ & $73 \pm 3$ & $0.87 \pm 0.08$ \\
\hline Survival \% & $0.90 \pm 0.10$ & $0.86 \pm 0.03$ & $1.01 \pm 0.06$ & $75.6 \pm 1$ \\
\hline
\end{tabular}

Each value is the mean \pm SEM of triplicate groups. All data were analyzed with one way ANOVA and no differences were found between treatments. Weight gain = Final weight - Initial weight. BWI: body weight increase $=[($ Final weight - Initial weight)/Initial weight $] \times 100$. SGR: specific growth rate $($ weight $)=[100 \times($ In final fish wt. - In initial fish wt.) $] / 45$ days. SGR (length) $=[100 \times$ (In final fish Ls. - In initial fish Ls.)]/45 days. K: Condition Factor= (weight/Total length $\left.{ }^{3}\right) \times 100$. DFC: daily food consumption $=$ food consumed per day per tank / number of fry in the tank. FER: feed efficiency ratio= Weight gain/Food consumption. DM: dry matter. SI: Standard length. BW: body weight. WG: weight gain. 
TABLE 3. Fatty acid composition (percentage of total fatty acids) of total lipid of pejerrey fry feed with the experimental diets.

\begin{tabular}{|c|c|c|c|c|}
\hline Fatty acid/Diet & $0 \% \mathrm{SfO}$ & $50 \%$ SfO & $80 \%$ SfO & $100 \%$ SfO \\
\hline $14: 0$ & $1.21 \pm 0.03 \mathrm{a}$ & $1.10 \pm 0.03 a$ & $0.908 \pm 0.04 b$ & $0.85 \pm 0.03 \mathrm{~b}$ \\
\hline $14: 1$ & $0.12 \pm 0.01 \mathrm{a}$ & $0.120 \pm 0.004 \mathrm{a}$ & $0.110 \pm 0.002 \mathrm{a}$ & $0.09 \pm 0.004 b$ \\
\hline $15: 0$ & $0.37 \pm 0.02 \mathrm{a}$ & $0.34 \pm 0.01 \mathrm{ab}$ & $0.301 \pm 0.007 b$ & $0.29 \pm 0.02 b$ \\
\hline $16: 0$ & $20.7 \pm 0.4 \mathrm{a}$ & $20.1 \pm 0.8 \mathrm{a}$ & $17.3 \pm 0.3 b$ & $17.3 \pm 0.7 b$ \\
\hline $16: 1 n-9$ & $0.67 \pm 0.02$ & $0.67 \pm 0.01$ & $0.69 \pm 0.02$ & $0.66 \pm 0.03$ \\
\hline $16: 1 n-7$ & $4.37 \pm 0.06 \mathrm{a}$ & $3.1 \pm 0.1 \mathrm{~b}$ & $2.73 \pm 0.05 c$ & $2.33 \pm 0.04 \mathrm{~d}$ \\
\hline $16: 2$ & $0.30 \pm 0.01$ & $0.32 \pm 0.01$ & $0.27 \pm 0.05$ & $0.25 \pm 0.04$ \\
\hline $17: 0$ & $0.55 \pm 0.02 \mathrm{a}$ & $0.46 \pm 0.01 \mathrm{~b}$ & $0.35 \pm 0.02 \mathrm{~cd}$ & $0.34 \pm 0.02 \mathrm{~d}$ \\
\hline $16: 3$ & $0.61 \pm 0.01 \mathrm{a}$ & $0.470 \pm 0.005 b$ & $0.41 \pm 0.02 \mathrm{~cd}$ & $0.37 \pm 0.02 \mathrm{~d}$ \\
\hline $16: 4$ & $0.020 \pm 0.004$ & $0.02 \pm 0.01$ & $0.07 \pm 0.05$ & $0.04 \pm 0.02$ \\
\hline 18:0 & $5.2 \pm 0.2$ & $5.9 \pm 0.4$ & $5.0 \pm 0.2$ & $5.4 \pm 0.3$ \\
\hline $18: 1 n-9$ & $19.3 \pm 0.3 \mathrm{a}$ & $19.8 \pm 0.5 \mathrm{a}$ & $23.1 \pm 0.5 \mathrm{~b}$ & $22.5 \pm 0.2 b$ \\
\hline 18:1n-7 & $4.26 \pm 0.06 a$ & $3.39 \pm 0.04 b$ & $3.15 \pm 0.06 b c$ & $3.0 \pm 0.1 c$ \\
\hline $18: 2 n-6$ & $11.0 \pm 0.2 \mathrm{a}$ & $16.3 \pm 0.6 \mathrm{~b}$ & $20.40 \pm 0.06 \mathrm{~cd}$ & $21.8 \pm 0.9 \mathrm{~d}$ \\
\hline $18: 3 n-6$ & $0.75 \pm 0.06 \mathrm{a}$ & $1.66 \pm 0.05 b$ & $3.244 \pm 0.3 c$ & $3.97 \pm 0.3 d$ \\
\hline $18: 3 n-3$ & $1.03 \pm 0.03 a$ & $0.81 \pm 0.06 \mathrm{~b}$ & $0.753 \pm 0.008 b$ & $0.67 \pm 0.04 \mathrm{~b}$ \\
\hline $18: 4 n-3$ & $0.57 \pm 0.03 a$ & $0.40 \pm 0.03 b c$ & $0.35 \pm 0.02 \mathrm{~cd}$ & $0.28 \pm 0.02 \mathrm{~d}$ \\
\hline $20: 0$ & $0.17 \pm 0.01$ & $0.18 \pm 0.02$ & $0.147 \pm 0.008$ & $0.150 \pm 0.004$ \\
\hline $20: 1 n-9$ & $1.78 \pm 0.03 \mathrm{a}$ & $1.23 \pm 0.04 b c$ & $1.10 \pm 0.07 c$ & $0.89 \pm 0.03 d$ \\
\hline 20:1n-7 & $0.270 \pm 0.004 \mathrm{a}$ & $0.199 \pm 0.002 \mathrm{ab}$ & $0.164 \pm 0.002 \mathrm{ab}$ & $0.08 \pm 0.03 b$ \\
\hline $20: 2 n-6$ & $0.30 \pm 0.01 \mathrm{a}$ & $0.35 \pm 0.01 b$ & $0.38 \pm 0.02 b$ & $0.39 \pm 0.02 b$ \\
\hline 21:0 & $0.21 \pm 0.01 \mathrm{a}$ & $0.41 \pm 0.02 b$ & $0.89 \pm 0.03 c$ & $1.03 \pm 0.04 \mathrm{~d}$ \\
\hline $20: 3 n-6$ & $0.04 \pm 0.01 \mathrm{a}$ & $\mathrm{Ob}$ & $0.003 \pm 0.002 b$ & $\mathrm{Ob}$ \\
\hline $20: 4 n-6$ & $1.23 \pm 0.05$ & $1.19 \pm 0.06$ & $1.09 \pm 0.06$ & $1.2 \pm 0.1$ \\
\hline $20: 3 n-3$ & $0.16 \pm 0.01 \mathrm{a}$ & $0.11 \pm 0.01 b c$ & $0.092 \pm 0.002 c$ & $0.07 \pm 0.01 \mathrm{~d}$ \\
\hline $20: 4 n-3$ & $0.36 \pm 0.01 \mathrm{a}$ & $0.23 \pm 0.03 b c$ & $0.19 \pm 0.01 \mathrm{~cd}$ & $0.14 \pm 0.02 d$ \\
\hline $20: 5 n-3$ & $2.04 \pm 0.09 a$ & $1.51 \pm 0.07 b$ & $0.94 \pm 0.04 \mathrm{~cd}$ & $0.88 \pm 0.03 d$ \\
\hline $22: 0$ & $0.07 \pm 0.01 \mathrm{a}$ & $0.12 \pm 0.01 b$ & $0.114 \pm 0.006 \mathrm{~b}$ & $0.11 \pm 0.01 \mathrm{~b}$ \\
\hline $22: 1 n-11$ & $0.40 \pm 0.05$ & $0.30 \pm 0.04$ & $0.29 \pm 0.01$ & $0.290 \pm 0.004$ \\
\hline $22: 1 n-9$ & $0.26 \pm 0.02 a b$ & $0.22 \pm 0.02 b$ & $0.16 \pm 0.01 \mathrm{~cd}$ & $0.150 \pm 0.005 \mathrm{c}$ \\
\hline 22:1n-7 & $0.05 \pm 0.01$ & $0.05 \pm 0.01$ & $0.058 \pm 0.003$ & $0.05 \pm 0.001$ \\
\hline $22: 4 n-6$ & $0.08 \pm 0.01$ & $0.06 \pm 0.01$ & $0.086 \pm 0.004$ & $0.07 \pm 0.01$ \\
\hline $22: 5 n-622: 3 n-3$ & $0.330 \pm 0.01 \mathrm{a}$ & $0.310 \pm 0.01 \mathrm{ab}$ & $0.46 \pm 0.02 c$ & $0.540 \pm 0.004 \mathrm{c}$ \\
\hline $22: 5 n-3$ & $1.43 \pm 0.03 a$ & $1.09 \pm 0.08 b$ & $0.84 \pm 0.03 \mathrm{~cd}$ & $0.76 \pm 0.03 d$ \\
\hline $22: 6 n-3$ & $16.1 \pm 0.3 \mathrm{a}$ & $13.6 \pm 0.3 \mathrm{~b}$ & $10.8 \pm 0.5 \mathrm{~cd}$ & $10.8 \pm 0.5 d$ \\
\hline $24: 0$ & $0.57 \pm 0.02$ & $0.66 \pm 0.09$ & $0.453 \pm 0.03$ & $0.50 \pm 0.05$ \\
\hline 24:1 & $0.02 \pm 0.01$ & $0.02 \pm 0.01$ & $0.007 \pm 0.006$ & 0 \\
\hline Saturated & $29.1 \pm 0.7$ & $29 \pm 1$ & $25.5 \pm 0.5$ & $26 \pm 1$ \\
\hline Monounsaturated & $31.5 \pm 0.5$ & $29.2 \pm 0.7$ & $31.5 \pm 0.6$ & $30.1 \pm 0.3$ \\
\hline PUFA n-6 & $14.7 \pm 0.2 \mathrm{a}$ & $20.6 \pm 0.4 \mathrm{~b}$ & $26.4 \pm 0.2 c$ & $28.6 \pm 0.8 d$ \\
\hline PUFA n-3 & $21.8 \pm 0.2 \mathrm{a}$ & $17.8 \pm 0.4 \mathrm{~b}$ & $14.0 \pm 0.6 \mathrm{~cd}$ & $13.6 \pm 0.5 d$ \\
\hline
\end{tabular}




\begin{tabular}{|c|c|c|c|c|}
\hline EPA + DHA & $18.1 \pm 0.3$ & $15.1 \pm 0.3$ & $11.8 \pm 0.6$ & $11.7 \pm 0.5$ \\
\hline DHA/EPA & $7.9 \pm 0.3 \mathrm{a}$ & $9.0 \pm 0.2 \mathrm{~b}$ & $11.5 \pm 0.2 \mathrm{c}$ & $12.7 \pm 0.4 \mathrm{c}$ \\
\hline
\end{tabular}

Different letters indicate significant differences between diets $(n=6$ fish per treatment, one-way ANOVA, SNK, p<0.05). PUFA: poly unsaturated fatty acid. EPA: eicosapentaenoic acid. DHA: docosahexaenoic acid. 

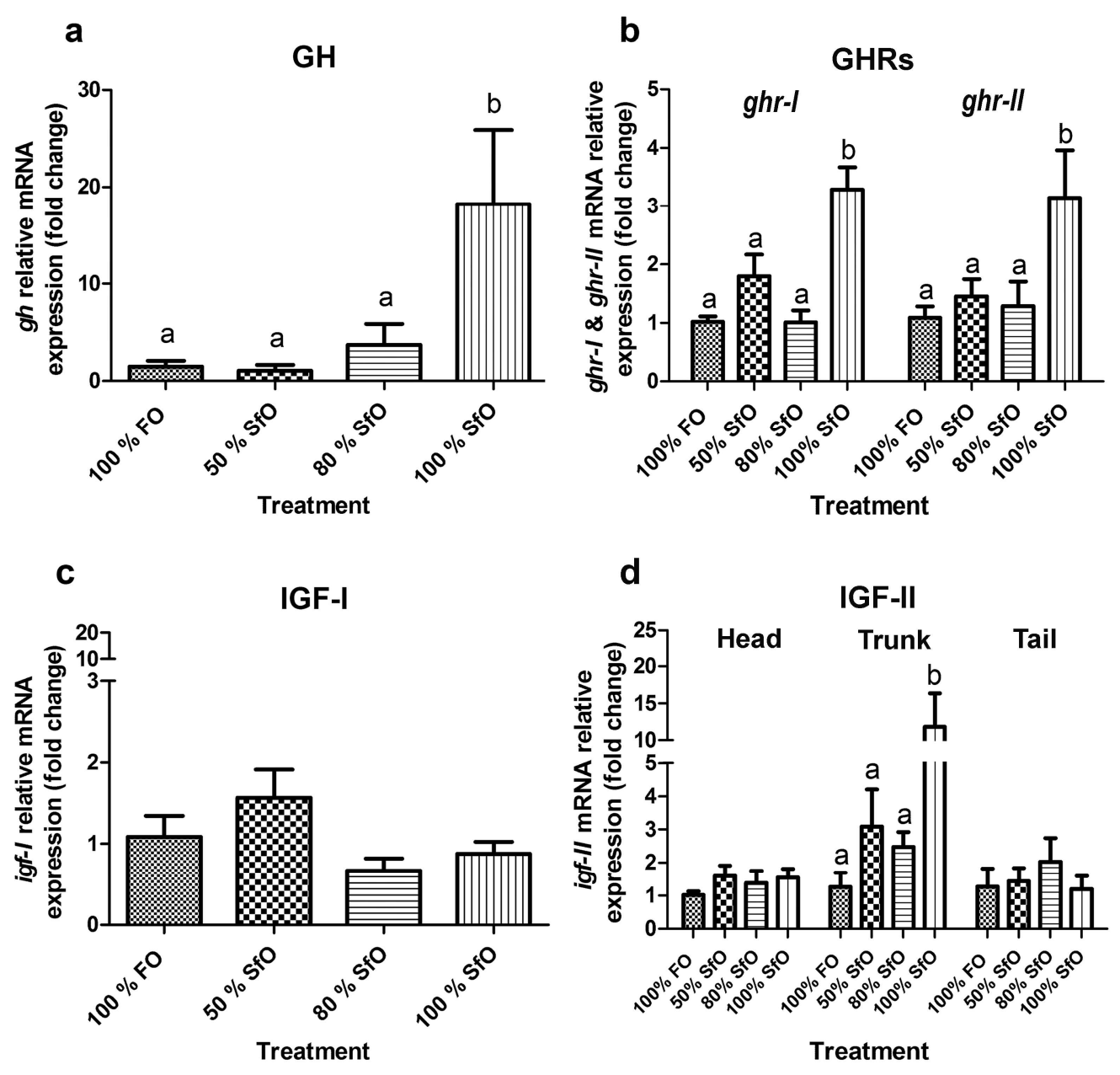

Fig 1. 

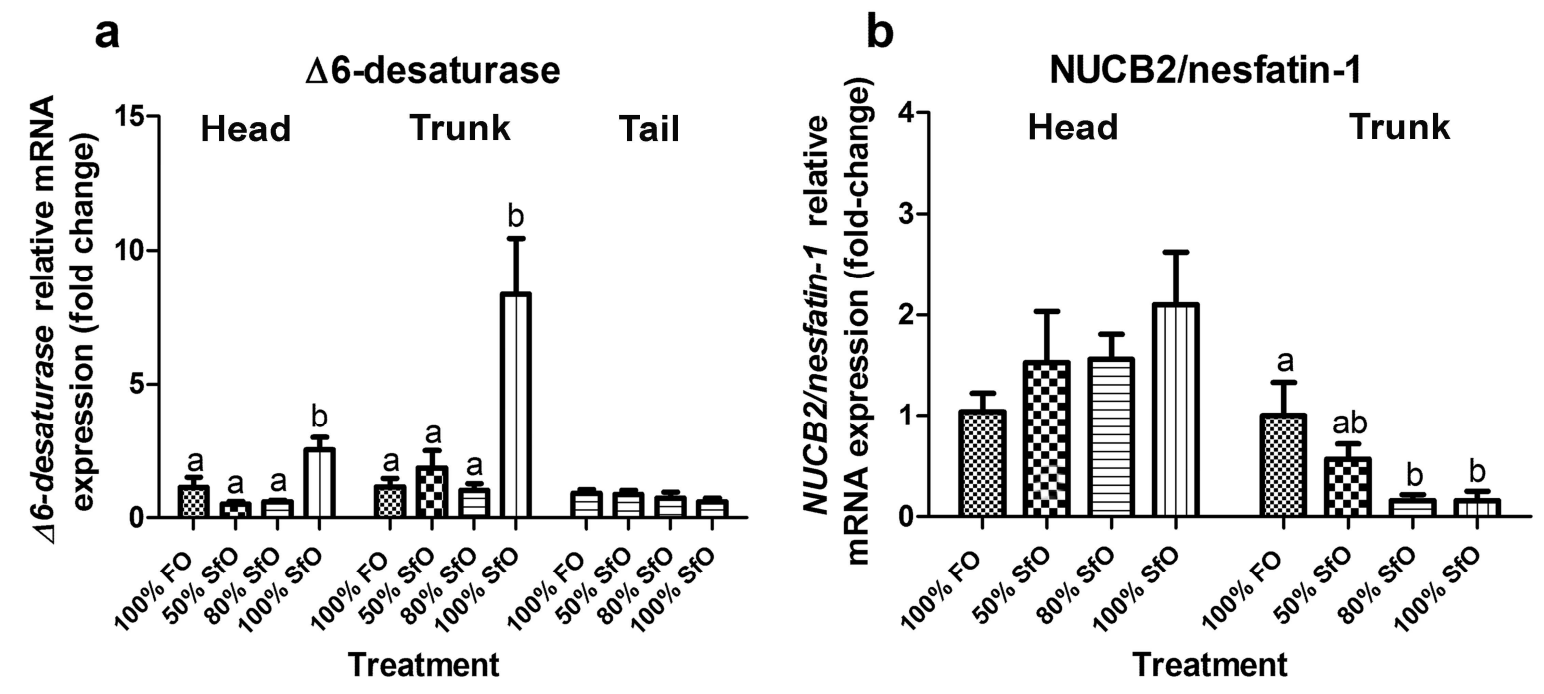

Fig 2.
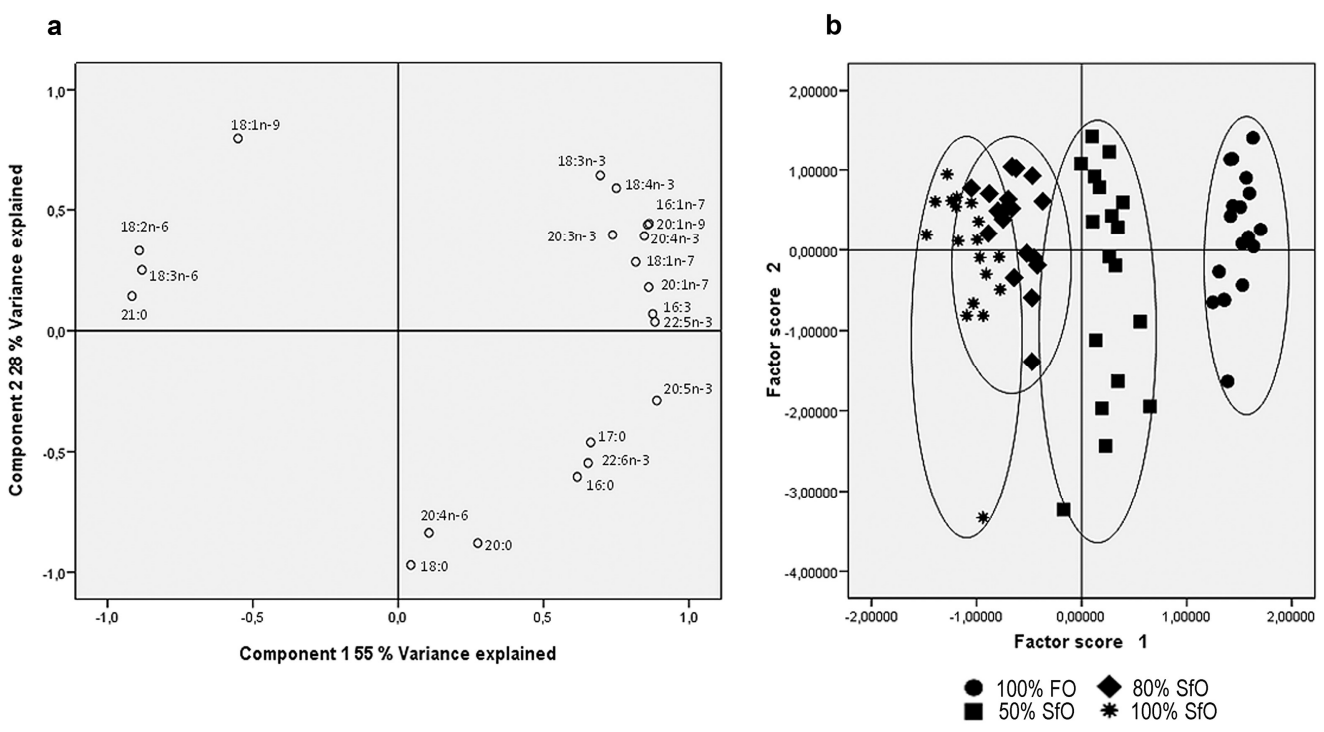

Fig 3. 
